\title{
Haemato-biochemical Alterations in Sheep Due to Experimentally Induced Haemonchus contortus Infection
}

\author{
Dipali Parmar*, Dinesh Chandra, Arvind Prasad, Ekta Singh, \\ Navneet Kaur* and Abdul Nasir \\ Division of Parasitology, ICAR-Indian Veterinary Research Institute, \\ Izatnagar, Uttar Pradesh, India \\ *Corresponding author
}

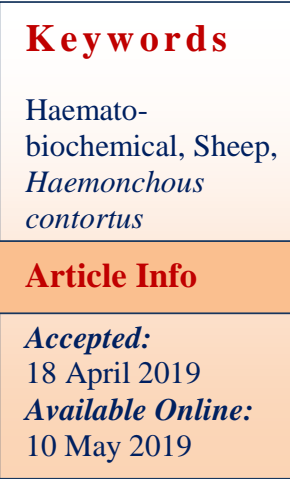

A B S T R A C T

Among all the gastrointestinal nematodes belonging to family Trichostrongylidae, Haemonchus contortus is the most prevalent and highly pathogenic nematode causing severe loss to small ruminant production system. Parasite causes alterations in various physiological parameters with disturbances in haemato-biochemical blood profile. Experiment was conducted in eighteen $(n=18)$ non-descript sheep that were randomly divided into two groups, infected (Group-A) and (Group-B) the negative control. Group- A animals were infected with 10,000 L3 of H.contortus. Larvae for the infective dose were obtained through coproculture of faeces of previously infected sheep. Animals were stall fed and were maintained separately in the animal shed to prevent infection. Haematological (Hb, PCV, TLC, DLC) and biochemical parameters (Total protein, albumin, globulin) were monitored at weekly intervals in both the groups. Results of the present study concluded that infection with H.contortus led to disturbance in haemopoietic system that led to alterations in blood haemo-biochemical profile. Mean $\mathrm{Hb}$ level in case of infected group (Group-A) declined from $10.83 \pm 0.59$ to $4.97 \pm 0.83$ at 5 th week post infection (PI). Similarly, PCV dropped from 24.08 \pm 0.59 to $14.52 \pm 1.90$. Mean Hb and PCV values for negative control (Group-B) remained within normal range i.e. $11.07 \pm 0.21$ and $30.99 \pm 0.83$. Leucocyte count started declining from third week PI in Group-A. By 28 days PI neutrophila and eosinophilia was observed in Group-A. Decline in albumin levels was more pronounced in infected group and reached up to $2.54 \pm 0.13 \mathrm{~g} / \mathrm{dl}$ at $3 \mathrm{rd}$ week post infection. No changes were observed in serum albumin levels throughout experiment in negative control group. Albumin to globulin ratio decreased significantly in group A on $3^{\text {rd }}, 4^{\text {th }}$ and $5^{\text {th }}$ week post infection as compared to negative control group.

\section{Introduction}

Sheep and goat farming is a major source of income in developed and developing countries. According to the Food and Agriculture Organisation (FAO, 2013) overall sheep population for the year 2012 was 1.2 billion worldwide, dominated by Asia (44.9\%), then Africa (27.6\%) and followed by America (7.3\%). Majority of farm animals are infected with several species of gastrointestinal (GI) nematodes that evolved 
from their free living forms due to lack of oxygen (Suntherland and Scott, 2010). Among these, Haemonchus contortus, Trichostrongylus colubriformis are highly evolved and are major production limiting infection in sheep and goat.

Disease occurrence is more common in tropical and subtropical countries due to hot and humid climatic conditions (Urquhart et al., 1996). Haemonchosis can occur in all age groups. However, animals between 2-24 months are more susceptible. Main pathogenic effects are caused by late larval stages and adult worms (Taylor et al., 2007; Bowman, 2014) which attach themselves to abomasal mucosa and feed upon blood leading to an average blood loss of 0.05-0.07 $\mathrm{ml} /$ parasite (Malviya et al., 1979; Soulsby, 1982). Haemonchus is among the most fecund strongly lid nematodes with a pre patent period of 18-21 days. Clinical haemonchosis is mainly classified into three types depending upon intensity of worm burden that is hyperacute, acute and chronic form (Soulsby, 1982; Taylor et al., 2007). Acute haemonchosis is most common in India and is characterised by anaemia, hypoprotenemia and development of bottle jaw condition (Soulsby, 1982).

Main economic losses are due to reduced weight gain and prolonged emaciation because of impaired digestion and decreased absorption of protein, calcium and phosphorus (Sood, 1981). About 30-40\% mortality has been reported in lambs due to haemonchosis if no timely treatment with proper anthelmintic is undertaken (Kalita et al., 1978).

\section{Materials and Methods}

\section{Study area and location}

Present study was conducted from January 2018 to June 2018 under the project, Network programme on gastrointestinal parasitism at Division of Parasitology, Indian Veterinary Research Institute, Izatnagar, Uttar Pradesh, India on local indigenous sheep procured from nearby village at Bareilly. The flock was located in the subtropical region of India at $28^{\circ} 23^{\prime} 34.8^{\circ} \mathrm{N} 79^{\circ} 25^{\prime} 59.9^{\circ} \mathrm{E}$.

\section{Experimental sheep flock}

Experiment was conducted on eighteen $(n=18)$ non-descript, indigenous sheep with age less than one year. Deworming was done with Levamisole @ $7.5 \mathrm{mg} / \mathrm{kg}$ body and Fenbendazole @5mg/kg body weight before start of the experiment to clear up any preexisting parasitic infection. To check concurrent infection with coccidia, all animals were treated with Amprolium @ 1g/20kg body weight for five consecutive days. Before start of the experiment, Faecal Egg Count (FEC) was zero for all animals.

\section{Coproculture for infective larvae of $\boldsymbol{H}$.} contortus

Fresh faeces from sheep infected with H.contortus (donor animals) were collected and pooled. Coproculture was performed on the collected faeces as per standard technique to harvest fresh $\mathrm{L}_{3}$ larvae (Anon, 1971) which were identified microscopically for $H$. contortus utilizing morphological key (Levine, 1961). Sheep of group A were infected with 10,000 H.contortus larvae given per os. Control animals of Group B were kept infection free.

\section{Haemato-biochemical examination}

Blood samples were collected from all the experimental sheep both infected and control at weekly interval from day 0 to 35 days PI. The haemoglobin concentration ( $\mathrm{Hb} \%)$, Packed Cell Volume (PCV), Total Leukocyte Count (TLC), Differential Leukocyte Count 
(DLC) were determined. Biochemical parameters included total serum protein, serum albumin, serum globulin and albumin/globulin ratio utilizing commercially available kits.

\section{Clinical observations}

Following experimental infection, all animals were monitored regularly for development of clinical signs of haemonchosis, if any. During the course of experiment, infected sheep were observed for development of change in the colour of eye conjunctiva, bottle jaw, body condition, body weight gain and constipation etc which are indicative of haemonchosis.

\section{Results and Discussion}

\section{Coprological examination}

Following infection, eggs appeared in the faeces from 17-21 DI (Pre patent period) in animals of infected Group A. All the animals of infected group were positive for eggs of $H$. contortus by 21 days PI. However, eggs were absent in the control animals (Group-B) throughout the experiment.

\section{Haematological parameters}

Significant differences in haematological values among both groups were observed which is presented in Table 1. At third week post infection (PI), there was slight reduction in $\mathrm{Hb}$ and $\mathrm{PCV}$ level in the infected group. Thereafter a sharp decline in $\mathrm{Hb}$ and PCV level was observed in infected group till end of the experiment. Mean $\mathrm{Hb}$ level in case of infected group (Group-A) declined from $10.83 \pm 0.59$ to $4.97 \pm 0.83$ respectively at 5 th week post infection. Similarly, PCV dropped from $24.08 \pm 0.59$ to $14.52 \pm 1.90$. Mean $\mathrm{Hb}$ and PCV values for negative control (Group-B) remained within normal range i.e. $11.07 \pm 0.21$ and $30.99 \pm 0.83$ as compared to infected group.
Statistically significant difference $(\mathrm{p}<0.05)$ was found in RBC count on $4^{\text {th }}$ and $5^{\text {th }}$ week post challenge. Total leukocyte count was highest in Group-A on second week post infection i.e. $15.62 \pm 0.76$. Normal range of total leukocyte count ranges from 4$10 \times 103 / \mu 1$ for sheep. Leukocyte count started declining from third week PI in Group-A. By 28 DPI neutrophila and eosinophilia was observed in Group-A.

\section{Biochemical parameters}

\section{Total protein and albumin}

Total protein value gradually declined from second week post challenge up to fourth week in infected group. Sharp decrease in infected group was observed in which values decreased from $7.41 \pm 0.21 \mathrm{~g} / \mathrm{dl}$ to $5.94 \pm 0.25$. As expected from the result of total protein values, levels started to decrease from two weeks post infection when compared with the negative control group. Decline in albumin levels was more pronounced in infected group and reached up to $2.54 \pm 0.13 \mathrm{~g} / \mathrm{dl}$, respectively at $3 r d$ week post infection. No changes were observed in serum albumin levels throughout experiment in negative control group. Albumin to globulin ratio decreased significantly in group $\mathrm{A}$ on $3^{\text {rd }}, 4^{\text {th }}$ and $5^{\text {th }}$ week post infection as compared to negative control group.

In the infected group lower globulin levels $(3.49 \pm 0.20)$ on fourth week PI was recorded as compared to negative control (3.77 \pm 0.17$)$ (Table 2).

\section{Clinical observations}

All animals from infected group showed pale conjunctiva during initial weeks $\left(2^{\text {nd }}\right.$ and $3^{\text {rd }}$ week) of parasite establishment. During peak period of infection $\left(5^{\text {th }}\right.$ and $6^{\text {th }}$ week) conjunctiva became almost white with 
FAMACHA score falling in the range of 4 and 5. Animals became lethargic and showed depressed body conditions, decrease in body weight which was significant by $35^{\text {th }}$ day PI.

Table.1 Haematological alteration at different time interval in H. contortus infected (Group A) and control sheep (Group B)

\begin{tabular}{|c|c|c|c|c|c|c|}
\hline \multirow{2}{*}{ Weeks } & \multicolumn{2}{|c|}{ Haemoglobin (g/dl) } & \multicolumn{2}{c|}{ PCV (\%) value } & \multicolumn{2}{c|}{ TLC $\left(\mathbf{1 0}^{3} / \boldsymbol{\mu l}\right)$} \\
\cline { 2 - 7 } & Group A & Group B & Group A & Group B & Group A & Group B \\
\hline $\mathbf{0}$ & $10.83 \pm 0.59$ & $9.84 \pm 0.36$ & $24.08 \pm 0.59$ & $24.25 \pm 1.06$ & $13.92 \pm 0.88$ & $9.17 \pm 0.49$ \\
\hline $\mathbf{1}$ & $10.56 \pm 0.79$ & $10.13 \pm 0.47$ & $28.27 \pm 2.19$ & $27.26 \pm 1.26$ & $13.68 \pm 0.84$ & $9.21 \pm 0.41$ \\
\hline $\mathbf{2}$ & $10.04 \pm 0.49$ & $11.05 \pm 0.36$ & $27.24 \pm 2.37$ & $28.49 \pm 0.95$ & $15.62 \pm 0.76$ & $8.75 \pm 41$ \\
\hline $\mathbf{3}$ & $7.28 \pm 0.74$ & $11.05 \pm 0.30$ & $20.10 \pm 2.05$ & $29.72 \pm 0.89$ & $13.12 \pm 0.98$ & $9.88 \pm 0.72$ \\
\hline $\mathbf{4}$ & $5.18 \pm 0.66$ & $11.02 \pm 0.21$ & $16.61 \pm 1.60$ & $29.79 \pm 1.06$ & $11.68 \pm 0.76$ & $10.24 \pm 0.71$ \\
\hline $\mathbf{5}$ & $4.97 \pm 0.83$ & $11.07 \pm 0.21$ & $14.52 \pm 1.90$ & $30.99 \pm 0.83$ & $9.86 \pm 0.72$ & $11.25 \pm 1.45$ \\
\hline
\end{tabular}

Table. 2 Biochemical parameters at different time interval in $H$. contortus infected (Group A) and control sheep (Group B)

\begin{tabular}{|c|c|c|c|c|c|c|}
\hline \multirow{2}{*}{ Weeks } & \multicolumn{2}{|c|}{ Total protein (g/dl) } & \multicolumn{2}{c|}{ Albumin (g/dl) } & \multicolumn{2}{c|}{ Globulin(g/dl) } \\
\cline { 2 - 7 } & Group A & Group B & Group A & Group B & Group A & Group B \\
\hline $\mathbf{0}$ & $7.41 \pm 0.21$ & $7.57 \pm 0.41$ & $3.61 \pm 0.09$ & $3.48 \pm 0.15$ & $3.93 \pm 0.25$ & $3.96 \pm 0.49$ \\
\hline $\mathbf{1}$ & $7.13 \pm 0.15$ & $7.46 \pm 0.28$ & $3.68 \pm 0.14$ & $3.53 \pm 0.12$ & $3.53 \pm 0.30$ & $3.78 \pm 0.19$ \\
\hline $\mathbf{2}$ & $6.92 \pm 0.19$ & $7.52 \pm 0.14$ & $3.70 \pm 0.10$ & $3.03 \pm 0.13$ & $3.84 \pm 0.17$ & $3.81 \pm 0.09$ \\
\hline $\mathbf{3}$ & $6.02 \pm 0.19$ & $7.46 \pm 0.16$ & $3.68 \pm 0.17$ & $2.54 \pm 0.14$ & $3.58 \pm 0.16$ & $3.78 \pm 0.29$ \\
\hline $\mathbf{4}$ & $5.94 \pm 0.25$ & $7.44 \pm 0.11$ & $3.67 \pm 0.10$ & $2.51 \pm 0.13$ & $3.49 \pm 0.20$ & $3.77 \pm 0.17$ \\
\hline
\end{tabular}

Results showed first appearance of eggs in the faeces of animals during 17-21 DPI which was almost similar to prepatent period reported earlier which is 18-21 days for $H$. contortus (Souls by, 1982, Shakya et al., 2009).

Since $\mathrm{Hb}$ level and PCV is considered a true phenotypic indicator for the estimation of severity of clinical haemonchosis. Variations in parameters like haemoglobin and PCV due to blood feeding activities of adult parasites in the abomasum. During the present study, notable blood loss was observed, It was evident by reduced haemoglobin and haematocrit values, which has also been earlier reported by previous workers (Abdel, 1992; Misra et al., 1996; Ishfaq, 2016). Rapid drop in these parameters was observed from third week to fifth week, which was statistically significant $(\mathrm{p}<0.05)$. Both male and female worms feed upon blood by attaching themselves to the abomasal mucosa through dorsal lancet (Soulsby, 1982). Parasite release a protein, calreticulin that binds with calcium hence preventing blood coagulation thereby assisting in blood feeding activity (Suchitra and Joshi, 2005).

In the later course of experiment, at $4^{\text {th }}$ week, leucopenia along with significant increase in eosinophil and neutrophil count was observed in infected Group-A. This may be attributed due to depletion of leucocytes that were active during initial stages of infection and actively participated in various immune mechanisms. Eosinophils are main antiparasitic effector cells that function particularly against non 
phagocytable organisms like helminths (Behm et al., 2000). Eosinophilia is well documented in H.contortus infected animals as well as in animals infected with other nematode and has been well correlated with protection (Fawzi et al., 2014; Huang et al., 2016).

Hypoproteinemia is a common condition in clinical and chronic haemonchosis (Soulsby, 1982) due to wastage of total protein and albumin through bite wounds of $H$. contortus as well as catabolism of protein. Reduction in total protein and albumin are well documented in H.contortus infection due to blood loss, haemorrhagic gastritis and increased permeability of mucosa leading to protein leakage from the gastric mucosa. In our study, decreased protein and albumin levels were evident from second week post infection. Statistically significant difference $(p<0.05)$ was observed in infected group on $28^{\text {th }}$ day post challenge compared to negative control. The results can be well correlated to studies carried out by other workers. Ahmad et al., (1989) reported a marked decrease in albumin levels, decrease in $\mathrm{Hb}, \mathrm{PCV}$ and $\mathrm{RBC}$ which are directly proportional to the nematode infection. There was negative energy balance in the infected group which led to significant variation in weight in infected animals (Group-A) as compared to control animals (Group-B).

In conclusion, haemato-biochemical alterations in sheep infected with $10,000 \mathrm{~L}_{3}$ of H.contortus could produce clinical disease showing significant changes in the haematobiochemical parameters. Clinical signs like bottle jaw and anaemia were present in the infected animals with this infective dose. Hypoprotenemia, hypoalbumenia and hyperglobunemia condition could be recorded. The study revealed that with an infective dose of $10,000 \mathrm{~L}_{3}$ of H.contortus alterations in blood profile could be produced which was due to its blood feeding activity of adult Haemonchus worms. Severity of the pathogenic effects combined with high prolific/ fecundity rate makes it an economically important parasite in small ruminants. Various Haemato-biochemical parameters significantly lowered. Decreased $\mathrm{Hb}, \mathrm{PCV}$ and $\mathrm{RBC}$ count in infected group were manifested as clinical signs of pale conjunctiva. Total leucocyte count showed marked leucopenia due to depletion of immune cells. Damage caused by infected Haemonchus worms to sheep was severe that affected the overall production status of animal. Hence, making H.contortus an economically important parasite.

\section{References}

Abdel, A.T.S. 1992. Haematological ad Biochemical studies on the efficiency of synthetic drugs against gastrointestinal nematode parasites in sheep. Australian veterinary journal of medicine. 42: 197-203.

Ahmad, M. and Ansari, J.A., 1989. Effect of Haemonchosis on haematology and non specific phosphomonoesterase activities in sheep and goats. Helminthologia, 26(4), pp.295302.

Anon, 1971. Manual of Veterinary Parasitological Laboratory Techniques, Technical Bulletin No. 18, Her Majesty's Stationery Office, Ministry of Agriculture, Fisheries and Food, London, U. K., pp. 14 - 19.

Behm, C.A. and Ovington, K.S. 2000. The role of eosinophils in parasitic helminth infections: insights from genetically modified mice. Parasitol. Today. 16: 202-209.

Bowman, D.D. 2014. Georgis' Parasitology for Veterinarians-e-Book. Elsevier Health Sciences.

FAO, S. 2013. FAOSTAT database. Food and 
Agriculture Organization of the United Nations, Rome, Italy.

Fawzi, E. M., Gonzalez-Sanchez, M., Corral, M., Cuquerella, M. and Alunda, J. 2014. Vaccination of lambs against Haemonchus contortus infection with a somatic protein (Hc23) from adult helminths. Int. J. Parasitol. 44: 429436.

Huang, L. and Appleton, J.A. 2016. Eosinophils in helminth infection: defenders and dupes. Trends in parasitol. 32: 798-807.

Ishfaq, 2016. Evaluation of immunoprotection in sheep immunised with immunodominant polypeptides of somatic antigen of Haemonchus contortus. Thesis, M.V.Sc. Deemed University, Indian Veterinary Research Institute, Izatnagar, India.

Kalita, C. L., Gautam, O. P. and Banerjee, D. P. 1978. Fenbendazole against Haemonchosis in sheep. Indian Vet. J. 55: 660-662.

Levine, ND (1961). Protozoan parasites of domestic animals and man. 1st Edn., Minneapolis, Burgess Publishing Co., P: 189.

Malviya, H. C., Pathanaik, B., Tiwari, H. C. and Sharma, B. K. 1979. Measurement of the blood loss caused by Haemonchus contortus infection in sheep. Indian Vet. J. 56: 709-710.

Misra, S.C., Panda. D.N., Prida. S. 1996.
Haematological and histological alterations of immature paramphistomiasis in lambs. Indian veterinary journal. 73: 1274-1276.

Shakya, K.P., Miller, J.E. and Horohov, D.W., 2009. A Th2 type of immune response is associated with increased resistance to Haemonchus contortus in naturally infected Gulf Coast Native lambs. Vet parasitol. 163:57-66.

Sood, M. L. 1981. Haemonchus in India. Parasitol. 83: 639-650

Soulsby, E. J. L. 1982. Helminths, arthropods and protozoa of domesticated animals (No. Ed. 7). Bailliere Tindall.

Suchitra, S. and Joshi, P. 2005. Characterization of Haemonchus contortus calreticulin suggests its role in feeeding and immune evasion by the parasites. Biochem. Et. Biophys. Acta. 172: 293-303.

Sutherland, I. and Scott, I. 2010. Nematode parasites. Gastrointestinal Nematodes of Sheep and Cattle. Oxford: Wiley Blackwell. 1-26.

Taylor, M.A., Coop, R.L., Wall, R.L. 2007. Veterinary Parasitology. Third ed. Blackwell Publishing. 159-161

Urquhart, G. M. Armour. J., Duncan, JL., Dunn, AM and Jennings, FW. 1996. Veterinary Parasitology 2nd edition Blackwell Science Ltd, Oxford, UK.

\section{How to cite this article:}

Dipali Parmar, Dinesh Chandra, Arvind Prasad, Ekta Singh, Navneet Kaur and Abdul Nasir. 2019. Haemato-biochemical Alterations in Sheep Due to Experimentally Induced Haemonchus contortus Infection. Int.J.Curr.Microbiol.App.Sci. 8(05): 2371-2376.

doi: https://doi.org/10.20546/ijcmas.2019.805.280 